\title{
Analysis on Teaching Reform of Optical Fiber Communication in Higher Vocational Schools
}

\author{
Hechuan $^{1, \text { a }}$ \\ ${ }^{1}$ (ChongQing College of Electronic Engineering, ChongQing, 401331,China)
}

\begin{abstract}
Keywords: Optical Fiber Communication, Higher Vocational Schools, Teaching Reform
\end{abstract}
\begin{abstract}
From the theory and practice teaching two aspects, this paper conduct in-depth discussion of optical fiber communication teaching courses and propose to strengthen the theoretical, practical experience and expand their horizons and encourage innovative teaching basic philosophy to cultivate high-quality and innovative ability talent.
\end{abstract}

\section{Introduction}

Optical fiber communication technology is a rapid development of science, specifically to study how light the way information is transmitted over fiber. Through the study of optical fiber communication course, we can master the system in a variety of fiber optic technology to transmit information, an overview of the optical fiber communication technology, and the transmission characteristics of the fiber has a deep and thorough understanding of the familiar optical communication system architecture and basic principle. The course subjects and the nature of their course content is characterized by complex, mainly in many types, requiring more and more publicity, more forms, graphics and more; the basics of physics are more involved (field theory of optics, etc.); and engineering practice more closely linked; the application of qualitative theory more occasions. . This course introduces the optical fiber communication systems theory and technology. Course requirements through this course can enable students to master the basic principles of fiber optic communication technology, the basic structure of optical fiber communication systems and system design methods to understand the practical applications and the latest developments in the direction of the optical fiber communication technology, for students after graduation to engage the fiber optic digital communication equipment, maintenance, design, construction or lay a good foundation for further studies. "Optical Fiber Communication" as the application of a strong curriculum, there are many problems in practical Course. On "Optical Fiber Communication" Theory and Practice of teaching reform has become the university research.

\section{Cultivation Orientation and Training Course Requirements}

Optical fiber communication is backbone communication engineering professional courses to train and improve application ability, innovation and research capability of undergraduate college students as the basic goal. Training requirements we propose is: Through this course, students are more comprehensive grasp of the basic concepts of optical fiber communication, basic theories and key technologies, understand and master the performance analysis and system design method of optical fiber communication systems, understanding of modern fiber-optic communication new technology development and application. This part is to lay the necessary foundation for the further study of optical fiber communication networks and related technologies. Concrete is should have: transfer theory and analysis methods fiber; works semiconductor light source, a semiconductor photodetector and passive optical components and characteristics; Optical basic components and the parts function; composition and system design optical fiber communication system; $1 / 2$ basic principles of light and optical fiber communication network of new technologies; basic principles and methods of measuring $3 / 4$ optical fiber communication systems.

\section{The Reasons for Optical Fiber Communication Problems}

From the point of view taught in the traditional mode of teaching, are generally in accordance with 
the natural order of textbooks to explain step by step, as the multi-course formulas, tables and more graphics and more, and in the classroom, teachers need to do a lot on the blackboard the derivation of mathematical analysis, classroom excessive derivation, shown to lead classroom atmosphere dull, poor teaching. In addition, the course grade assessment methods relatively simple. Currently assessment "Optical Fiber Communication" Principle Course to take a more traditional closed-book examination methods and examination content to theoretical knowledge based, resulting in student learning dull, rote habit of showing a lack of ability to compare the integrated application of knowledge, can not fully reflect the students' course knowledge mastery, creative thinking ability to solve practical problems. For these reasons a great blow to all students' enthusiasm.

In the process of engineering colleges, "Optical Fiber Communication" in teaching practice, practice teaching has always been a short board. With the new theories and new technologies continue to produce optical fiber communication and development of experimental hardware upgrade of backward, outdated laboratory equipment, a single pilot projects, experimental content aging and other reasons, the teaching content has lagged behind the development of optical communication technology. In addition, the use of packaging is strong and experimentally tests the degree of integration in the box easy to operate while it can not allow students to understand the whole picture of optical fiber communication systems. Practice hard to achieve the purpose of teaching students practical ability, resulting in lack of experimental teaching students generally recognized, seriously affecting the quality of teaching and experimental results.

Due to the physical basics of optical fiber communication technology are more involved, such as field theory, the principle of optical communication technology, laser technology. Therefore, prior to this course, students should Prerequisite these courses. However, due to the difficulty, it has relatively deep these courses, so many students difficult to fully grasp. Usually cylindrical coordinates Helmholtz equation solution of a given boundary conditions to complete the study by separation of variables such as fiber distribution model, require students to have good mathematical skills and knowledge in terms of electromagnetic waves, if the basics solid enough this part of the learning difficulties will appear. Students acquire knowledge limited to simply back the conclusions, formulas, do the math. Students do not understand the significance of engineering theory, no specific analysis of the problem, leading to lack of student awareness of course, there do not know what there is to learn the use of the phenomenon, these problems will make the students gradually lose interest in this course.

\section{Theory of Teaching Reform}

Optical fiber transmission theory of knowledge related to electromagnetic fields and electromagnetic waves more aspects of the content of the abstract, complex formulas, such as the principle of light in optical fiber transmission fluctuations, its derivation is very complicated abstract, causing students to understand it is very difficult. This requires teachers to have a very deep knowledge of physics and mathematics, before class to make full stock of knowledge, careful preparation, it can be handy in teaching. Proposed the introduction of computer-assisted instruction in the teaching process, such as the use of Matlab software which will simplify mathematical derivation and analysis process, so that the corresponding entity to analyze specific image presented to the students; while some textbooks graphics into Flash animation production, students We can understand the abstract theory.

Optics part mainly relates to optical fiber communication and optical switch for use in an array, the combination optical passive devices, fiber grating, fiber lasers, optical amplifiers, optical wavelength converter, MEMS devices, opto-electronic integrated devices. Thus teaching the optical device portion should try to take the theory and practice of teaching. Due to financial constraints, in the case of laboratories do not buy the correlation of optical devices, can show the appearance and application of various types of optical components by means of multimedia to students, students do not have to compensate for perceptual defect. In addition, in the teaching process should concentrate on the development status of these optical devices of recent and future trends.

In recent years, the rapid development of optical communication, its new technologies emerging, 
if the teacher is limited to the contents of the books, you can not expand the students' knowledge horizons. Therefore, it is recommended in the teaching process as follows: the collected data to optical fiber communication technology multimedia way to teach students and to show that the part of the students has specific knowledge. The students were divided into several groups, each collecting different content of new fiber-optic communications technology, then each group selected a representative from these representative introduced its / findings to the class. In this way students can develop team spirit and inspire independent learning awareness.

\section{Experimental Teaching Reform}

Optical fiber communication theory experiment is an important complement to classroom teaching, select its contents both in close contact with the theory, but also facilitate student demonstration experiment or experiments, students experiment firm grasp of theoretical knowledge.

First of all, it should be appropriate to create some type of experimental verification, validation Experiment students a solid grasp of the basic theoretical knowledge and familiarity with the use of a common instrument for the conduct of comprehensive experiments and lay a solid foundation. Second, it should encourage students interested in the use of existing laboratory resources Designing Experiment. They use CPLD module optical fiber communication experiment box on the secondary development. It can improve the ability of students participating in the experiment enthusiasm and further training of students. In addition, experimental teaching should be used in optical fiber communication system simulation software simulation. With the rapid development of information science, research and development, testing equipment update faster, improve the technical content, the price of more expensive equipment, the use of optical fiber communication system simulation can compensate for the lack of equipment to some extent. In the simulation, students can freely adjust the amplitude, frequency and phase of the simulation waveforms, feel free to add the size of the noise and so on, to the entire transport system, as small as a device to optimize the design and performance simulation, visual analog information in optical fiber communication the entire transmission process. Use simulation to facilitate students to observe and learn, helping to train the students' practical ability and innovative thinking.

Heavy theory, light practice, results-light process is characteristic of traditional evaluation methods. Therefore the establishment of this course to reflect the overall situation of the evaluation system is necessary. It proposed to increase the proportion of students' achievement of the learning process, improve student achievement proportion of the experimental section. In theory course final exam results can be used part, keynote presentations, class discussion integrated approach several achievements, which fully reflects the student's learning process and learning. Experimental results including the use of basic experiment, comprehensive experiment and design of experiments and simulations construction parts. For the design of the experiment have higher requirements, results in the form of scientific papers written for students and post-graduate studies thesis foundation. All in all, the establishment of a comprehensive evaluation system contribute is to a comprehensive test students on the course of learning, stimulate students' motivation to learn.

\section{Conclusion}

Taking into account the characteristics of optical fiber communication course, in the process of teaching practice in optical fiber communication course, emphasize the spirit of theoretical teaching and practical teaching base, highlight the application of the integration of education reform ideas, we set up the experimental part of the course as well as a variety of strengthening teaching methods and other aspects of the implementation of the application of innovative education. All of those are to enable students to increase knowledge of the principles of optical communication, while take efforts to improve the basic understanding of the theory, practical ability to apply their knowledge and scientific literacy, complemented with content characteristics, so that to make students have a strong interest in learning knowledge of optical fiber communication technology and change boring learning to hands- in hand knowledge. 


\section{References}

[1] Li Liming, Chen Yeling. Cultivation of theoretical teaching students creative thinking [J]. Wuhan: Hubei Institute of Education, 2005, (11): 105-107

[2] Zheng Jiamao, Pan Xiaohui. Theoretical teaching, practice teaching, independent research study, four in one network to build student teaching mode [J]. Beijing: China University Teaching, 2008, (12): 4-7

[3] Xu Juan, Xu Mingya. On Information Theory and Coding Theory curriculum theory and teaching practice [J]. Guangzhou: Guangdong University of Technology (Social Science Edition), 2003, (3) Supplement: 126-128

[4] Zhang Fangping. Strengthen the practice of teaching to promote innovation Talents [J]. Beijing: China Higher Education, 2007, (17): 29-31

[5] Geng Tao, Ran Tiangang. Experimental Teaching Based on project-based fiber-optic communication [J]. Science Laboratory, 2011, (5) 